\title{
Çok kilit sistemli ve çok fonksiyonlu femur intramedüller çivi sistemi
}

\author{
Multi-functional femoral intramedullary nail (FIN) system \\ having multi-locking system
}

\author{
Fuat Akpınar \\ İstanbul Medeniyet Üniversitesi Tıp Fakültesi, Ortopedi ve Travmatoloji Ana Bilim Dalı, İstanbul
}

\begin{abstract}
$\mathrm{Bu}$ buluş, femur kemiklerinin baş kırıkları dışında tekli veya çoklu kırılmalarında kemiklerin sabitlenerek kaynamasını sağlayan çoklu kilit sistemine sahip, çok fonksiyonlu femoral intramedüller çivi sistemidir. Buluş, antegrad veya retrograd yöntemle sağ veya sol femur kemiği için aynı sistemin kullanıldığı bir çivi ve çivinin proksimal tarafında kompresyon da uygulayabilen, beş ayrı açıda kilitleme sağlayan yedi adet kilitleme deliği ve distal ucunda iki adet kilitleme deliği içermektedir. Çivi ayrıca, geleneksel çivilerden farklı olarak distal ucunda distal destekleme vidasına skopi kullanmadan kolaylıkla yerleşerek kilitlemeyi sağlayan ve bu sayede erken hareket ve yüklenmeye izin veren kama şeklindeki bir uç içermektedir.
\end{abstract}

Anahtar sözcülkler: femur; intramedüller çivi; çoklu kilitleme sistemi

\section{T. C. Türk Patent Enstitüsü'ne Patent Belgesi için Başvuru Bilgileri ${ }^{[1]}$}

Başvuru bilgileri Tablo 1'de gösterilmiştir. ${ }^{[1]}$

Tablo 1. Başvuru bilgileri[1]

$$
\begin{aligned}
\text { Başvuru numarası: } & 2009 / 04246 \\
\text { Başvuru tarihi: } & 01.06 .2009 \\
\text { Başvuru şekli: } & \text { Ulusal başvuru } \\
\text { Evrak numarası: } & 2009-\mathrm{G}-117771 \\
\text { Evrak tarihi: } & 01.06 .2009 \\
\text { Tescil numarası: } & 200904246 \\
\text { Tescil tarihi: } & 21.07 .2015 \\
\text { Koruma tipi: } & \text { Patent } \\
\text { Başvuru sahipleri: } & \text { Fuat Akpınar } \\
\text { Buluş sahipleri: } & \text { Fuat Akpınar }
\end{aligned}
$$

\begin{abstract}
This invention is the multi functional femoral intramedullary nail system having multi locking system which provides union by fixing bones in case of single or multiple fractures of femoral bones except head and neck fractures. The invention includes a nail using the same system for the right or left femur bone by antegrade or retrograde method, and seven locking holes that can apply compression on the proximal side of the nail and provide locking at five different angles and 2 locking holes at the distal end. Unlike conventional nails, the nail also includes a wedge-shaped tip at the distal end that allows easy insertion and locking on the distal supporting screw without using a fluoroscope, thus allowing early movement and loading.
\end{abstract}

Key words: femur; intramedullary nail; multiple locking system

\section{Teknik Alan ${ }^{[1]}$}

"Bu buluş, femur kemiğinin parçalı veya tekli kırılmalarında, kemiğin sabitlenerek kaynamasını sağlayan çok kilit sistemli ve çok fonksiyonlu femur intramedüller çivi sistemi ile ilgilidir."

\section{Önceki Teknik/Teknikler ${ }^{[1]}$}

“Günümüzde, femur kemiği ile ilgili problemlerde çok farklı tespit yöntemleri kullanılmaktadır. Diğer uzun (tubuler) kemiklerde olduğu gibi, femur için de intramedüller kilitli çivi tespiti son yıllarda endikasyonları genişletilerek yaygın olarak kullanılmaktadır. Yeni çivi sistemi arayışları, özellikle distal kilit vidalarının geçirilmesinde yaşanan problemlere bağlı ameliyat süresinin uzaması, küçük çaplı çivi kullanımında çivi ve kilit vidası kırılmaları, erken yük verdirilememe, skopi kullanım süresi uzamasına bağlı radyasyon maruziyeti gibi olumsuzluklar için ideal intramedüller tespit yönteminin geliştirilememiş olmasındandır.”

- İletişim adresi: Prof. Dr. Fuat Akpınar, S.B. Göztepe Prof. Dr. Süleyman Yalçın Şehir Hastanesi, Ortopedi ve Travmatoloji Kliniği, İstanbul Tel: 0546 - 6368801 e-posta: fuatakpinar@yahoo.com ORCID iD: 0000-0001-9399-8516

- Geliștarihi: 8 Kasım $2020 \quad$ Kabul tarihi: 21 Kasım 2020 


\section{Buluşun Kısa Tarifi[1]}

" $\mathrm{Bu}$ buluş, kullanılmakta olan mevcut kilitli intramedüller tespit yöntemlerinin dezavantajlarını gidermeyi amaçlamaktadır.

Bu amaçlara ulaşmak üzere, antegrad veya retrograd yöntemle sağ veya sol femur kemiği için aynı sistemin kullanıldığı bir çivi ve çivinin proksimal tarafinda kompresyon da uygulayabilen, beş ayrı açıda kilitleme sağlayan yedi adet kilitleme deliği ve distal ucunda 2 adet kilitleme deliği ve geleneksel çivilerden farklı olarak distal ucunda distal destekleme vidasına skopi kullanmadan ya da kullanım süresini belirgin kısaltan, kolaylıkla yerleşerek kilitlemeyi sağlayan ve bu sayede erken hareket ve yüklenmeye izin veren kama şeklindeki ucu içeren çoklu kilit sistemli tasarıma sahip, çok kilit sistemli ve çok fonksiyonlu, femur başı hariç tüm femur problemlerinde tespit olanağı sağlayan farklı, yeni intramedüller kilitli çivi sistemi geliştirilmiştir.”

\section{Buluşun Detaylı Açıklanması ${ }^{[1]}$}

"Referans numaraları"1]: 1. Çok kilit sistemli ve çok fonksiyonlu femur intramedüller çivisinin gövdesi, 2. Çok kilit sistemli ve çok fonksiyonlu femur intramedüller çivisi gövdesinin kavislenmeye başladığı kısmı, 3. Çok kilit sistemli ve çok fonksiyonlu femur intramedüller çivisinin göndericiye bağlantı dişli deliği ve göndericiye sabitlenme kanalı, 4. Çok kilit sistemli ve çok fonksiyonlu femur intramedüller çivisinin yaklaşık 125$145 \mathrm{~mm}$ arası değişebilen düz kısmı, 5. Çok amaçlı oblik delik, 6. Sağ ve sol femur kemikleri için çivi eksenine göre distal ve proksimal olarak $130^{\circ}$; çok amaçlı oblik deliğe göre sağ ve sol $10^{\circ}$ açılanabilen delik, 7. Sağ ve sol femur kemikleri için çivi eksenine göre distal ve proksimal olarak $130^{\circ}$; çok amaçlı oblik deliğe göre săg ve sol $10^{\circ}$ açılanabilen delik, 8. Çok kilit sistemli ve çok fonksiyonlu femur intramedüller çivisinin kavisli gövde kısmı, 9. Çok kilit sistemli ve çok fonksiyonlu femur intramedüller çivisinin distal destekleme kilitleme vidasına girip kilitlemeyi sağlayan kama şeklindeki ucu, 10. Çok kilit sistemli ve çok fonksiyonlu femur intramedüller çivisinin distal destekleme kilitleme vidasına girip kilitlemeyi sağlayan kama şeklindeki ucunun çentik kısmı, 11. Çok kilit sistemli ve çok fonksiyonlu femur intramedüller çivisinin boydan boya olan deliği, 12. Distal destekleme kilitleme vidası, 13. Çivinin girdiği distal destekleme kilitleme vidasının yuvası, 14. Distal destekleme kilitleme vidası ile çiviyi birbirine kilitleyen setscrew yuvası, 15. Çok amaçlı oblik deliğe göre radial eksende sağa $12^{\circ}$ açılı delik, 16 . Çok amaçlı oblik deliğe göre radial eksende sola $12^{\circ}$ açılı delik, 17. Çok amaçlı oblik deliğe göre radial eksende sağa $6^{\circ}$ açılı delik, 18 . Çok amaçlı oblik deliğe göre radial eksende sola $6^{\circ}$ açılı delik, 19. Çok amaçlı oblik deliğe göre radial eksende sağa $6^{\circ}$ açılı delik, 20. Çok amaçı oblik deliğe göre radial eksende sola $6^{\circ}$ açılı oblik delik.

Bu buluş, Şekil 1 ve 2'de belirtildiği üzere; femur kemiğinin parçalı veya tekli kırılmalarında, kemiğin sabitlenerek kaynamasını sağlayan çok kilit sistemli ve çok fonksiyonlu femur intramedullar çivi (FIN) sistemi olup, özelliği; çok kilit sistemli ve çok fonksiyonlu femur intramedullar çivisinin (FIN) gövdesi (1), çok kilit sistemli ve çok fonksiyonlu femur intramedullar çivisi (FIN) gövdesinin (1) kavislenmeye başladığı kısmı (2), çok kilit sistemli ve çok fonksiyonlu femur intramedullar çivisinin (FIN) (1) göndericiye bağlantı dişli deliği ve göndericiye sabitlenme kanalı (3), çok kilit sistemli ve çok fonksiyonlu femur intramedullar çivisinin (FIN) (1) yaklaşık 125-145mm arası değişebilen düz kısmı (4), çok amaçlı oblik (eğik) delik (5), sağ ve sol femur kemikleri için çivi (1) eksenine distal ve proksimal olarak $130^{\circ}$, çok amaçlı oblik deliğe (5) göre sağ ve sol $10^{\circ}$ açılanabilen delik (6), sağ ve sol femur kemikleri için çivi (1) eksenine distal ve proksimal olarak $130^{\circ}$, çok amaçlı oblik deliğe (5) göre să̆ ve sol $10^{\circ}$ açılanabilen delik (7), çok kilit sistemli ve çok fonksiyonlu femur intramedullar çivisinin (FIN) (1) kavisli gövde kısmı (8), çok kilit sistemli ve çok fonksiyonlu femur intramedullar çivisinin (FIN) (1) distal destekleme kilitleme vidasına (DDKV) (12) girip kilitlemeyi sağlayan kama şeklindeki ucu (9), çok kilit sistemli ve çok fonksiyonlu femur intramedullar çivisinin (FIN) (1) distal destekleme kilitleme vidasına (DDKV) (12) girip kilitlemeyi sağlayan kama şeklindeki ucunun (9) çentik kısmı (10), çok kilit sistemli ve çok fonksiyonlu femur intramedullar çivisinin (FIN) boydan boya olan deliği (11), distal destekleme kilitleme vidası (DDKV) (12), FIN çivisinin (1) girdiği distal destekleme kilitleme vidasının (DDKV) (12) yuvası (13), distal destekleme kilitleme vidası (DDKV) (12) ile çok kilit sistemli ve çok fonksiyonlu femur intramedullar çivisini (FIN) (1) birbirine kilitleyen setscrew yuvası (14), çok amaçlı oblik deliğe (5) göre radial eksende să̆a $12^{\circ}$ açılı delik (15), çok amaçlı oblik deliğe (5) göre radial eksende sola $12^{\circ}$ açılı delik (16), çok amaçlı oblik deliğe (5) göre radial eksende sağa $6^{\circ}$ açılı delik (17), çok amaçlı oblik deliğe (5) göre radial eksende sola $6^{\circ}$ açılı delik (18), çok amaçlı oblik deliğe (5) göre radial eksende sağa $6^{\circ}$ açılı delik (19) ve çok amaçlı oblik deliğe (5) göre radial eksende sola $6^{\circ}$ açılı oblik delikten (20) meydana gelmesidir.

Günümüzde, femur kemiği ile ilgili problemlerde çok farklı tespit yöntemleri kullanılmaktadır. Diğer uzun kemiklerde olduğu gibi, femur için de intramedüller kilitli çivi tespiti son yıllarda endikasyonları genişletilerek yaygın olarak kullanılmaktadır. Yeni çivi sistemi arayışları, özellikle distal kilit vidalarının geçilmesinde yaşanan problemler, küçük çaplı çivi kullanımında çivi ve kilit vidası kırılmaları, erken yük verdirilememe, skopi kullanım süresi uzamasına bağlı yan etkiler gibi olumsuzluklar için ideal intramedüller tespit yönteminin geliştirilememiş olmasındandır.

Geliştirdiğimiz çivi modelinin önemli bazı teknik ve mekanik özellikleri; solid yapıda, yuvarlak, titanyum esnekliği ve biyouyumluluğa sahip olması, mekanik direncinin iyi olması, vida ve çivi kırılmalarına izin vermemesi, distal ucunun distal destekleme-kilitleme vidası ile uyumlu kama şeklinde olması, 
çivinin $12 \mathrm{~cm}-13 \mathrm{~cm}$ 'lik kısmının farklı çap ve boy seçeneklerinin olmasıdır.

Çivinin önemli uygulama özellikleri; kolayca çakılıp çıkarılabilmesi ve böylece ameliyat süresini kısaltması, oymalı ve oymasız kullanılabilmesi, kontrollü sıkışırma (kompresyon) yapabilmesi, distal ve proksimalde çok düzlemli stabilite să̆laması, proksimal ve distal kilitlemeyi kolayca yapabilmesi, skopi kullanım ihtiyacını ortadan kaldırması ya da en aza indirmesi, uçlardaki çivi migrasyonunu engellemesi, vida migrasyonunu engellemesi, tek planlı ve tek distal kilit vidası ile translasyonu engellemesi, dıs tespit ihtiyacını giderip erken harekete izin veren intramedüller tespit gerçekleştirmesi, tüm femur tespit problemlerinde tek bir çivi sistemi ile stabilizasyon sağlaması, hem să̆ ve sol femur için hem de antegrad ve retrograd kullanım için tek bir çivi sistemi ile çözüm getirmesidir. Kilitleme, kılavuz kullanımı ile \%100 başarılır.

Bir uçta kompresyona müsaade eden ve 5 ayrı açıda kilitleme sağlayan 1 adet oval oblik delik, sağ ve sol femur kemikleri için çivi eksenine distal ve proksimal olarak $130^{\circ}$, çok amaçlı oblik deliğe göre sağ ve sol $10^{\circ}$ açılanabilen 2 adet delik, birbirleri ile sagittal planda $24^{\circ}$ açll 2 adet delik, birbiri ile sagittal planda $12^{\circ}$ açılı 2 adet delik, olmak üzere 7 adet kilitleme deliği mevcuttur. Distal uçta 2 adet birbirleri ile sagittal planda $12^{\circ}$ açılı delik vardır. Kilitleme için özel tasarlanan distal destekleme- kilitleme vidası veya kilitli vidadan istenilenler birlikte kullanılabilir.
Diğer çivilere üstünlük sağlayabilecek farklılıkları; çoklu kilit sistemi ile çoklu düzlemde stabilizasyon sağlaması, kilit vidaları ve distal destekleme-kilitleme vidasının beraber kullanılabilmesi, çok fonksiyonlu olması, statik kilitleme, dinamik kilitleme (dinamizasyon veya otodinamizasyon), primer kompresyon yapabilmesi, antegrad veya retrograd olarak să̆ veya sol femur kemiği için aynı çivi sisteminin kullanılabilmesi, femur başı hariç tüm femurun tespit problemlerine tek bir çivi sistemi ile çözüm sağlamasıdır.

Sistemin kücü̈k çaplı çivilerinde distal kilit vida deliği bulunmamaktadır. Dar medüller kanallı femurlar için tercih edilirler ve yeterli mekanik dirence sahip olup, distal destekleme-kilitleme vidası ile kilitlenerek erken hareket ve yüklenmeye izin verir. Klasik çivilerde karşılaşılabilen vida deliğinin olduğu bölgede çivi veya kilit vidasının kırılması ve eklem içi migrasyonu gibi komplikasyonlara yol açmaz. Tek bir distal destekleme-kilitleme vidası ile kondiler bölgede distal kilitleme sağlanabilir. Distal destekleme-kilitleme vidası; aksiyel, rotasyonel, translasyonel ve farklı açılardaki kuvvetlere çivi ve vida kırılması olmadan maksimum direnme (multiplanar stabilite) sağlar. Distal destekleme-kilitleme vidası ile kilitlemede skopi ihtiyacı olmaz ya da azaltılır. Kılavuz sistemi ile kilitleme \%100 başarılabilir. Skopi kullanmaksızın distal destekleme- kilitleme vidası ile kilitlenmenin sağlanıp sağlanamadığı içindeki setscrew ile kontrol edilerek anlaşılabilir.

Femur başı hariç femurun tüm bölgelerinin kırıklarında ve tespit endikasyonlarında, kötü kaynama veya kaynama

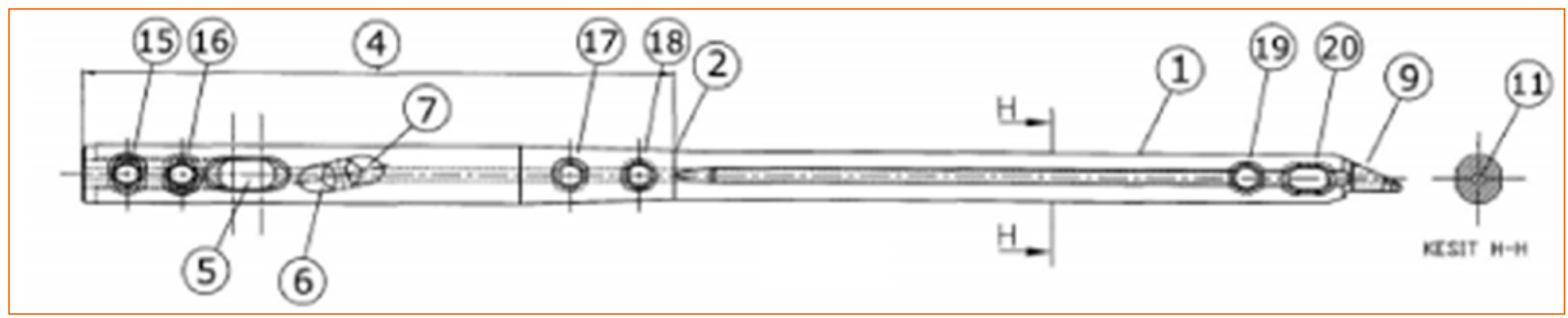

Şekil 1. Çok kilit sistemli ve çok fonksiyonlu femur intramedüller çivisinin yandan görünümüdür. ${ }^{[1]}$

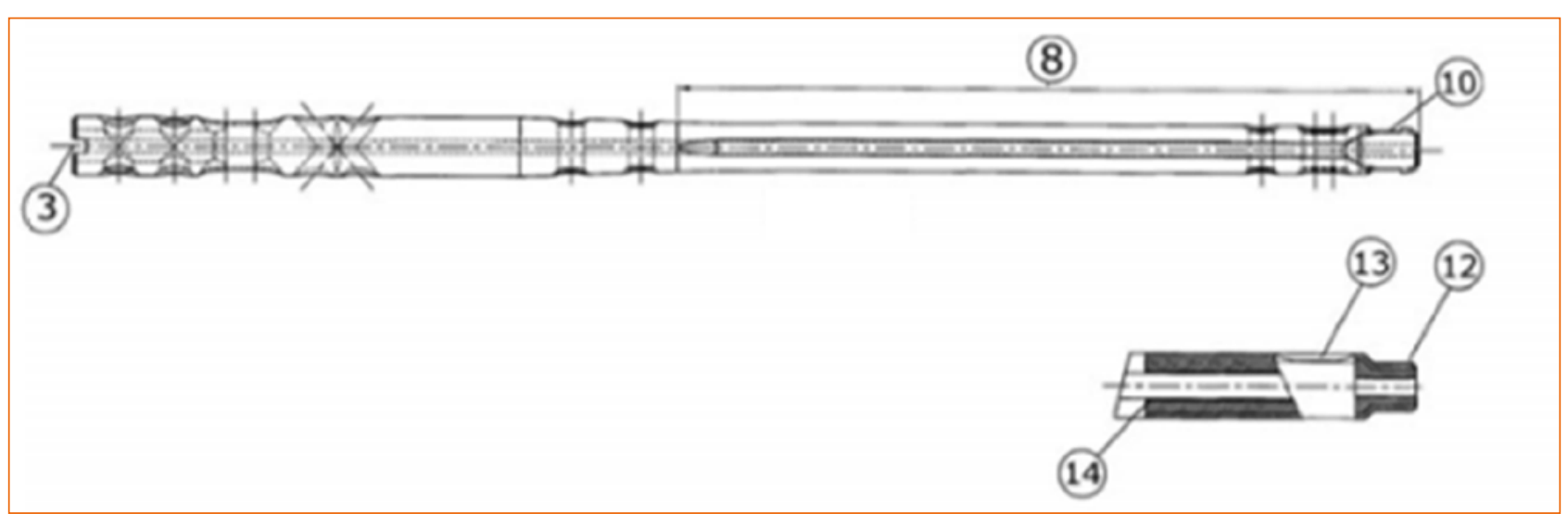

Şekil 2. Çok kilit sistemli ve çok fonksiyonlu femur intramedüller çivisinin önden görünümüdür. ${ }^{[1]}$ 
yokluğu durumlarında, kısaltma osteotomilerinde, tümör rezeksiyonlarında, kombine uzatmalarda (ekstramedullarintramedüller) kullanılabilir."

\section{İstemler ${ }^{[1]}$}

"1- Bu buluş, femur kemiğinin parçalı veya tekli kırılmalarında, kemiğin sabitlenerek kaynamasını sağlayan çok kilit sistemli ve çok fonksiyonlu femur intramedullar çivi (FIN) sistemi olup, özelliği; FIN çivisinin (1) bir ucunda (4) kompresyona müsaade eden ve 5 ayrı açıda kilitleme sağlayan 1 adet oval oblik (eğik) delik (5), sağ ve sol femur kemikleri için çivi (1) eksenine distal ve proksimal olarak $130^{\circ}$, çok amaçlı oblik deliğe (5) göre săg ve sol $10^{\circ}$ açılanabilen 2 adet delik (6), (7), birbirleri ile sagittal planda $24^{\circ}$ açılı 2 adet delik (15), (16), birbiri ile sagittal planda $12^{\circ}$ açılı 2 adet delik (17), (18) olmak üzere 7 adet kilitleme deliği, diğer ucunda 2 adet birbirleri ile sagittal planda 12 derece açılı delik (19), (20) bulunmasıdır. FIN çivisi (1), çok kilit sistemli ve çok fonksiyonlu femur intramedullar çivisinin (FIN) gövdesi (1), çok kilit sistemli ve çok fonksiyonlu femur intramedullar çivisi (FIN) gövdesinin (1) kavislenmeye başladığı kısmı (2), çok kilit sistemli ve çok fonksiyonIu femur intramedullar çivisinin (FIN) (1) göndericiye bağlantı dişli deliği ve göndericiye sabitlenme kanalı (3), çok kilit sistemli ve çok fonksiyonlu femur intramedullar çivisinin (FIN) (1) yaklaşık 125-145mm arası değişebilen düz kısmı (4), çok amaçı oblik (eğik) delik (5), sağ ve sol femur kemikleri için çivi (1) eksenine distal ve proksimal olarak $130^{\circ}$, çok amaçlı oblik deliğe (5) göre sağ ve sol $10^{\circ}$ açılanabilen delik (6), sağ ve sol femur kemikleri için çivi (1) eksenine distal ve proksimal olarak $130^{\circ}$, çok amaçlı oblik deliğe (5) göre să̆ ve sol $10^{\circ}$ açılanabilen delik (7), çok kilit sistemli ve çok fonksiyonlu femur intramedullar çivisinin (FIN) (1) kavisli gövde kısmı (8), çok kilit sistemli ve çok fonksiyonlu femur intramedullar çivisinin (FIN) (1) distal destekleme kilitleme vidası (DDKV) (12) yuvasına (13) girip kilitlemeyi sağlayan kama şeklindeki uсu (9), çok kilit sistemli ve çok fonksiyonlu femur intramedullar çivisinin (FIN) (1) distal destekleme kilitleme vidası (DDKV) (12) yuvasına (13) girip kilitlemeyi sağlayan kama şeklindeki ucunun çentik kısmı (10), çok kilit sistemli ve çok fonksiyonlu femur intramedullar çivisinin (FIN) (1) boydan boya olan deliği (11), distal destekleme kilitleme vidası (DDKV) (12), çok kilit sistemli ve çok fonksiyonlu femur intramedullar çivisinin (FIN) (1) girdiği distal destekleme kilitleme vidasının (DDKV) (12) yuvası (13), distal destekleme kilitleme vidası (DDKV) (12) ile çok kilit sistemli ve çok fonksiyonlu femur intramedullar çivisini (FIN) (1) birbirine kilitleyen setscrew yuvası (14), çok amaçlı oblik deliğe (5) göre radial eksende sağa $12^{\circ}$ açılı delik (15), çok amaçlı oblik deliğe (5) göre radial eksende sola $12^{\circ}$ açılı delik (16), çok amaçlı oblik deliğe (5) göre radial eksende sağa $6^{\circ}$ açılı delik (17), çok amaçlı oblik deliğe (5) göre radial eksende sola $6^{\circ}$ açıı delik (18), çok amaçlı oblik deliğe (5) göre radial eksende sağa $6^{\circ}$ açılı delik (19) ve çok amaçlı oblik deliğge (5) göre radial eksende sola $6^{\circ}$ açıı oblik delikten (20) meydana gelir.

2- Istem 1'de bahsedilen çok amaçlı oblik (eğik) delik (5) olup, özelliği; să̆ ve sol femur kemiği için kompresyon amaçı da kullanılabilmesi, dik veya açılı olarak vida göndermek için de kullanılabilmesidir.

3- İstem 1'de bahsedilen săg ve sol femur kemikleri için çivi (1) eksenine distal ve proksimal olarak $130^{\circ}$, çok amaçı oblik deliğe (5) göre să̆ ve sol $10^{\circ}$ açılanabilen delikler (6), (7) olup, özelliği; deliklerin (6), (7) săg ve sol femur kemikleri için çivi (1) eksenine distal ve proksimal olarak $130^{\circ}$, çok amaçlı oblik deliğe (5) göre să̆ ve sol $10^{\circ}$ açılanabilmesiyle karakterize edilir.

4- Istem 1'de bahsedilen çok kilit sistemli ve çok fonksiyonlu femur intramedullar çivisinin (FIN) (1) yaklaşık 125-145mm arası değişebilen düz kısmı (4) olup, özelliği; 125-145mm arası değişebilen boyda düz kısmının ve değişik çaplarının olmasıdır.

5- İstem 1'de bahsedilen çok kilit sistemli ve çok fonksiyonIu femur intramedullar çivisinin (FIN) (1) kavisli gövde kısmı (8) olup, özelliği; kavisli gövde kısmı üzerinde uç kısma yakın yuvarlak delik (19) ve oblik (eğik) delik (20) olmasıdır.

6- İstem 1'de bahsedilen çok kilit sistemli ve çok fonksiyonIu femur intramedullar çivisinin (FIN) (1) distal destekleme kilitleme vidası (DDKV) (12) yuvasına (13) girip kilitlemeyi sağlayan kama şeklindeki uсu (9) ve çok kilit sistemli ve çok fonksiyonlu femur intramedullar çivisinin (FIN) (1) distal destekleme kilitleme vidası (DDKV) (12) yuvasına (13) girip kilitlemeyi sağlayan kama şeklindeki ucunun (9) çentik kısmı (10) olup, özelliği; çok kilit sistemli ve çok fonksiyonlu femur intramedullar çivisinin (FIN) (1) distal destekleme kilitleme vidası (DDKV) (12) yuvasına (13) girip kilitlemeyi sağlayan kısmı olmasıdır.

7- Istem 1'de bahsedilen çok kilit sistemli ve çok fonksiyonlu femur intramedullar çivisinin (FIN) (1) boydan boya olan deliği (11) olup, özelliği; FIN çivisinin (1) bu delikten (11) geçen kılavuz tel ile gönderilmesini sağlamaktır.

8- İstem 1'de bahsedilen çok amaçlı oblik deliğe (5) göre radial eksende sağa $12^{\circ}$ açılı delik (15) olup, özelliği; deliğin (15), çok amaçlı oblik deliğe (5) göre radial eksende sağa $12^{\circ}$ açılı olmasıdır.

9- İstem 1'de bahsedilen çok amaçlı oblik deliğe (5) göre radial eksende sola $12^{\circ}$ açılı delik (16) olup, özelliği; 
deliğin (16), çok amaçlı oblik deliğe (5) göre radial eksende sola $12^{\circ}$ açılı olmasıdır.

10- İstem 1'de bahsedilen çok amaçlı oblik deliğe (5) göre radial eksende sağa $6^{\circ}$ açılı delik (17) olup, özelliği; deliğin (17), çok amaçlı oblik deliğe (5) göre radial eksende sağa $6^{\circ}$ açılı olmasıdır.

11- İstem 1'de bahsedilen çok amaçlı oblik deliğe (5) göre radial eksende sola $6^{\circ}$ açılı delik (18) olup, özelliği; deliğin (18), çok amaçlı oblik deliğe (5) göre radial eksende sola $6^{\circ}$ açılı olmasıdır.

12- İstem 1'de bahsedilen çok amaçlı oblik deliğe (5) göre radial eksende sağa $6^{\circ}$ açılı delik (19) olup, özelliği; deliğin (19), çok amaçlı oblik deliğe (5) göre radial eksende sağa $6^{\circ}$ açıı olmasıdır.

13- Istem 1'de bahsedilen çok amaçlı oblik deliğe (5) göre radial eksende sola $6^{\circ}$ açılı oblik delik (20) olup, özelliği; deliğin (20), çok amaçlı oblik deliğe (5) göre radial eksende sola $6^{\circ}$ açılı oblik olmasıdır."

\section{YAZARIN KONUYLA ILGILI ÇALIŞMALARI}

Günümüzde femur kırıkları kırık paternine ve etkilenen anatomik bölgeye göre birçok farklı tespit yöntemiyle tedavi edilebilmektedir. İntramedüller çivileme yaygın kabul gören ve endikasyonları artan bir yöntem haline gelmiş̧ir. Bu amaçla birçok çivi sistemi geliştirilmiştir. Femurun anatomik özellikleri, kompleks kırıklarda kırık redüksiyonunun zorluğu, implantın uygulama zorluğu, uygulama sırasında skopi kullanımına bağlı X-ışınlarına maruz kalınması, kaynama sorunları, implantın mekanik dayanımının yetmemesi gibi potansiyel sorunlar nedeniyle farklı tasarımlara ihtiyaç duyulmaktadır.

Yazarın yıllar içinde geliştirdiği birçok ortopedi ve travmatoloji alanındaki implant tasarımında olduğu gibi bu çivi modelinde de uygulama kolaylığı sağlaması, daha geniş endikasyonlarda kullanılabilmesi, skopi ihtiyacını ve X-ışını maruziyetini azaltması, implantın mekanik direncinin iyi olması, femurun proksimal ve distalindeki anatomik yapısına kolay uygulanabilmesi hedeflenmiştir.

Sonuçta; femurun baş bölgesi kırıkları haricindeki tüm femur kırıklarında kullanılabilen, hem proksimalde hem de distalde çok planda kolay kilitlenebilen, ihtiyaç halinde kompresyon sağlayabilen, kolayca dinamize edilebilen, solid yapısından dolayı küçük ve dar femoral kanallı hastalarda da sistemin küçük çaplı çivileriyle yeterli biyomekanik güce sahip, erken hareket ve yüklenme sağlayabilen "çok kilit sistemli ve çok fonksiyonlu femur intramedüller çivi sistemi" geliştirilmiş ve klinik ve biyomekanik çalışmalarda ${ }^{[2,3]}$ etkinliği gösterilmiştir.

\section{KAYNAKLAR}

1. Çok kilit sistemli ve çok fonksiyonlu femur intramedüller çivi sistemi T. C. Türk Patent Enstitüsü. Patent belgesi. No: 2009/04246. https://portal.turkpatent.gov.tr/anonim/arastirma/patent/ detayli

2. Saglam N, Kurtulmuş $T$, Saka G, İmam M, Abughalwa M, Akpinar F. Treatment offemoral shaft fractures with interlocking intramedullary nailing in adults. Injury 2012;43:S15. Crossref

3. Alemdar C, Küçükdurmaz F, DemirT, Azboy I, Demirtaş A, Bulut M, Aslan H. Distal kilit sistemi farklı yeni bir femur çivisi ile klasik femur çivisinin biyomekanik açıdan karşılaştırılması (S28-5). 24. Ulusal Türk Ortopedi ve Travmatoloji Kongresi, Antalya, Türkiye, 12-16 Kasım 2014. 